\title{
DIGITALCOMMONS
}

@WAYNESTATE -

Wayne State University

Kinesiology, Health and Sport Studies

College of Education

3-1-2010

\section{Validation of the Organizational Culture Assessment Instrument: An Application of the Korean Version}

\author{
Yun Seok Choi \\ Wayne State University \\ Minhee Seo \\ University of North Carolina at Greensboro \\ David Scott \\ University of New Mexico \\ Jeffrey J. Martin \\ Wayne State University, aa3975@wayne.edu
}

\section{Recommended Citation}

Choi, Y., Seo, M., Scott, D., \& Martin, J. J. (2010). Validation of the organizational culture assessment instrument: An application of the Korean version. Journal of Sport Management, 24(2), 169-189.

Available at: http://digitalcommons.wayne.edu/coe_khs/30 


\title{
Validation of the Organizational Culture Assessment Instrument: An Application of the Korean Version
}

\author{
Yun Seok Choi \\ Wayne State University \\ Minhee Seo \\ University of North Carolina - Greensboro \\ David Scott \\ University of New Mexico \\ Jeffrey Martin \\ Wayne State University
}

\begin{abstract}
The purpose of this study was to examine the psychometric properties of the Korean version of the Organizational Culture Assessment Instrument (OCAI) based on the Competing Values Framework (CVF). More specially, cultural equivalence between the Korean version and the original English version of the OCAI was evaluated using 39 bilingual Koreans. Next, a field test was conducted to examine scale reliability and construct validity of the Korean version of the OCAI using 133 organizational members from the Korean Professional Baseball League (KPBL). The findings indicate that the Korean version was successfully translated, items maintained the same meaning of the original OCAI items, and yielded acceptable psychometric properties making it applicable to Korean sport organizations.
\end{abstract}

With the rapid and remarkable market growth in the sport industry, various financial institutions have paid serious attention to its potential to be continuously successful. It is important for all industries to identify criteria that can be used to evaluate their overall organizational success. A substantial amount of attention has been paid to the concept of organizational culture in the past several years as one of the central elements that contribute to organizational success. Organizational cul-

Choi and Martin are with the Dept. of Kinesiology, Health, and Sport Studies, Wayne State University, Detroit, MI. Seo is with the Dept. of Education Psychology, University of North Carolina - Greensboro, NC. Scott is with the Dept. of Physical Performance and Development, University of New Mexico, Albuquerque, NM. 
ture refers to the basic pattern of shared values and assumptions governing the way employees within an organization think about and act on problems and opportunities (McShane \& Glinow, 2000). According to Schein (1992), organizational culture is described as widely shared values and assumptions that are clearly understood in an organization. In addition, Champoux (1996) proposed that organizational culture can be defined as dynamic values and is the deep aspect of an organization that shapes human behavior. Organizational culture also plays a significant role in contributing to organizational goals and is closely related to many managerial areas such as communication, decision-making process, effectiveness, leadership, and human resource management. Many scholars (e.g., Cameron \& Freeman, 1991; Cameron \& Quinn, 1999; Deal \& Kennedy, 1988; Lund, 2003; Paparone, 2003) in organizational studies have asserted that when an organization has strong culture and congruence, it is more effective than when it has a weak, incongruent, and disconnected culture. Identifying the unique nature of organizational culture in terms of cultural type, strength, and congruence assists in regaining organizational compositeness and revitalizing declining organizations (Cameron \& Freeman, 1991; Deal \& Kennedy, 1988; Denison \& Speitzer, 1991). Likewise, knowledge of organizational culture allows an organization to change the emphasis on certain values and to shift the focus by emphasizing the values in the cultural type identified as more desirable.

Several researchers (e.g., Cameron \& Quinn, 1999; Dennison \& Spreitzer, 1991; Ogbonna \& Harris, 2002; Paparone, 2003, Smith \& Shilbury, 2004) have also addressed the significant roles of creating, managing, and changing organizational culture for the purpose of increasing overall organizational effectiveness. In organizational behavior studies, organizational culture has been described as an essential predictor of organizational effectiveness (Amis \& Slack, 2002; Cameron \& Quinn, 1999; Colyer, 2000; Scott, 1997; Smith, 2004). For instance, Cameron and Quinn (1999) suggested that organizational culture is a central concept that powerfully influences organizational effectiveness. In addition, Delobbe, Haccoun, and Vandenberghe (2000) stressed that understanding organizational culture is one of the greatest theoretical tools needed to measure organizational effectiveness. Colyer (2000) also indicated that an analysis of organizational culture is a first step in measuring performance, effectiveness, and subsequent diagnosis of the cultural characteristics of an organization enforcing organizational values, business objectives, and goals used to evaluate organizational performances as standards. Thus, organizational theorists have recognized that culture has powerful effects on organizational performance as well as on long-term effectiveness.

In the field of sport management, the value of managing organizational culture has also been noted by several prominent scholars (e.g., Amis \& Slack, 2002; Colyer, 2000; Doherty \& Chelladurai, 1999; Scott, 1997; Shilbury \& Moore, 2006; Slack \& Parent, 2006; Smith \& Shilbury, 2004; Wallace \& Weese, 1995; Weese, 1996). Slack and Parent (2006) argued that the analysis of organizational culture can generate deep insights for sport managers about how to implement a new organizational culture and how to change the cultural environment within a sport organization. Amis, Slack, and Hinings (2004) suggested that diagnosing organizational culture within a sport organization is important to effectively deal with the rapid change of internal and external market environments. Papadimitriou and Taylor (2000) conducted research on organizational effectiveness in a sport management setting. In their study, they categorized organizational members called constituent groups 
(board members, paid administrative staff, technical staff, coaches, and athletes) and determined that each held different perception of effectiveness. According to their findings, various constituent groups within sport organizations often have their own dynamic subcultures that can be influenced by unit specific factors such as management and leadership styles, business objectives and strategic directions. In this scenario, each unit has the capacity to define effectiveness in ways that may be in conflict or in competition with those of other units. Thus, to effectively manage this conflict, it may be helpful for sport organizations to identify both macro (overall) and micro (subunit) perspectives of organizational culture affecting their long-term goals at the horizontal and vertical levels of organizational hierarchy. The rapid growth of professionalism and increased commercialization in the sport industry can have a significant impact on sport organizations. This changing environment should require sport organizations to review their organizational cultures for the purpose of determining how to enhance their effectiveness.

Although organizational culture has become a central concept for researchers in the analysis of various organizational phenomena, a literature review indicates that there is a lack of precision and consensus regarding its definition (Delobbe, Haccoun, \& Vandenberghe, 2000). It is still questionable how organizational culture should be observed, measured, or how different methods can be used to inform routine administration or organizational change. While some theorists measure organizational culture with specific and measurable variables, traits, or processes (Denison \& Spreitzer, 1991), others view it as a challenge to identify culture as an intrinsic value of the social environment that develops whenever people are brought together in a common enterprise. A third approach considers organizational culture as an anthropological phenomenon used to gain a better understanding of organizations as unique cultural types (Lund, 2004; Quinn \& Spreitzer, 1991).

Another controversy in studying organizational culture is that there has been little agreement among organizational scholars concerning the appropriate theoretical models for studying and understanding organizational culture (Howard, 1998; Schein, 1996; Smith, 2004). There is an assumption that organizations can be characterized according to cultural traits or dimensions common to all human organizations (Cameron \& Quinn, 1999). The most appropriate framework for any organizational culture study should be based on empirical evidence, should capture accurately the reality being described, and should be able to integrate and organize most of the dimensions of organizational culture being proposed (Cameron \& Quinn, 1999; Delobbe, Haccoun, \& Vandenberghe; 2000; Slack \& Parent, 2006; Zammuto \& Krakower, 1991). Realistically, because it is difficult to pay attention to every conceivable phenomenon of organizational culture, it is necessary to identify specific dimensions to diagnose an organization's culture.

In general, most scholars (e.g., Howard, 1998; Quinn \& Spreitzer, 1991; Schein, 1996; Xenikou \& Furnham, 1996) cite four major questionnaires that are widely used in most organizational culture studies: (a) Organizational Culture Profile (O'Reilly, Chatman, \& Caldwell, 1991), (b) Organizational Culture Index (Litwin \& Stringer, 1968; Wallach, 1983), (c) Organizational Culture Inventory (Cooke \& Lafferty, 1989), and (d) Competing Values Framework (Cameron \& Quinn, 1999; Quinn \& Spreitzer, 1991). There are several common dimensions of organizational culture used across these questionnaires that include cultural type, strength, management style, and congruence. 
Cameron and Freeman (1991) conducted a study with those major dimensions to assess the most powerful dimension accounting for effectiveness in colleges and universities. They found that three of the four cultural dimensions (cultural type, congruence, and strength) were equally important for measuring organizational culture. They also reported that cultural type, strength and congruence are the core dimensions of interest because these theoretical dimensions are strongly associated with higher degrees of organizational effectiveness. According to theoretical reviews of organizational culture studies, most scholars have identified cultural strength, type, and congruence as the most critical. As can be seen in the complexity of organizational culture, there are many different perspectives on this phenomenon. However, from this discussion, it should be apparent that there is no single right type of culture that an organization must have to be more effective or successful.

\section{The Competing Values Framework}

The framework selected for this study is the Competing Values Framework (CVF) originally proposed by Quinn and Rohrbaugh (1981). The CVF has advanced the measurement and comprehension of organizational culture constructs. For instance, the CVF can be used to specify the criteria (i.e., flexibility, stability, productivity, and planning) used to evaluate organizational effectiveness as a theoretical framework. In addition, it has been used to study leadership roles and effectiveness, organizational culture, change, and human resource development (Cameron \& Quinn, 1999; Lund, 2004; Quinn \& Cameron, 1983; Quinn, Faerman, Thompson, \& McGrath, 1990; Quinn \& Rohrbaugh, 1983; Shilbury \& Moore, 2006).

The CVF has been widely used to investigate organizational culture in many different areas such as business, education, and government, but has not been used to any extent in the sport industry. According to Cameron and Quinn (1999), the CVF has been considered as one of the 50 most important models in management science. In addition, the model has been employed in the improvement of thousands of organizations. Furthermore, Kwan and Walker (2004) also suggested that the CVF can be a useful tool in helping organizations study the change in organizational culture needed to reach a desired quality culture. Colyer (2000) addressed that the CVF might be a particularly useful in defining the organizational culture profile of sport organizations as a strategic attempt in organizational development. In addition to the usefulness of the CVF, Shilbury and Moore (2006) also noted that the CVF is an effective diagnostic tool to investigate similarities and differences of managerial roles at various levels of organizational hierarchy.

The CVF consists of four major cultural types (clan, adhocracy, market, and hierarchy) that are theorized to compose cultural profiles within many different types of organizational settings. The CVF has been widely used to assess types, congruence, and strengths of organizational cultures based on the core cultural values, assumptions, interpretations, and approaches that characterize organizations (Cameron \& Quinn, 1999). The CVF assumes that organizational culture cannot be characterized by a single cultural type because there are many subunits in an organization that have different cultures at various organizational levels (Cameron \& Quinn, 1999). Researchers (Cameron \& Freeman, 1991; Colyer, 2000; Deal \& Kennedy, 1988; Denison \& Spreitzer, 1991; Lund, 2004) profiling these cultural 
types have reported that organizations usually contain characteristics of more than one cultural type. Organizations tend to develop a dominant organizational culture over time as people in the organization adapt and respond to the challenges and changes in the environment. Thus, the CVF allows researchers to assess organizational culture and make recommendations for facilitating change within the organizations.

As a framework for studying organizational cultures, the CVF represents a departure from the qualitative approach that has characterized most cultural research. For example, the CVF is based on two theoretical dimensions: means and ends. An assumption of the CVF is that an organization possesses either a predominant internal emphasis or external focus. The CVF also refers to whether an organization strives for individuality and flexibility, or stability and control. These two dimensions create four main cultural types, each representing a distinct set of cultural values. The indicators consist of clan, adhocracy, market, and hierarchy. These indicators represent the different ends of two dimensions that constitute the rudiments of the CVF (Cameron \& Quinn, 1999). Notable in these four quadrants is that they represent competing assumptions regarding cultural values.

Analyzing organizational members' perceptions using quantitative methods can determine the characteristics of an organization that are evident according to the four cultural types. The results can be plotted on a chart to produce a visual

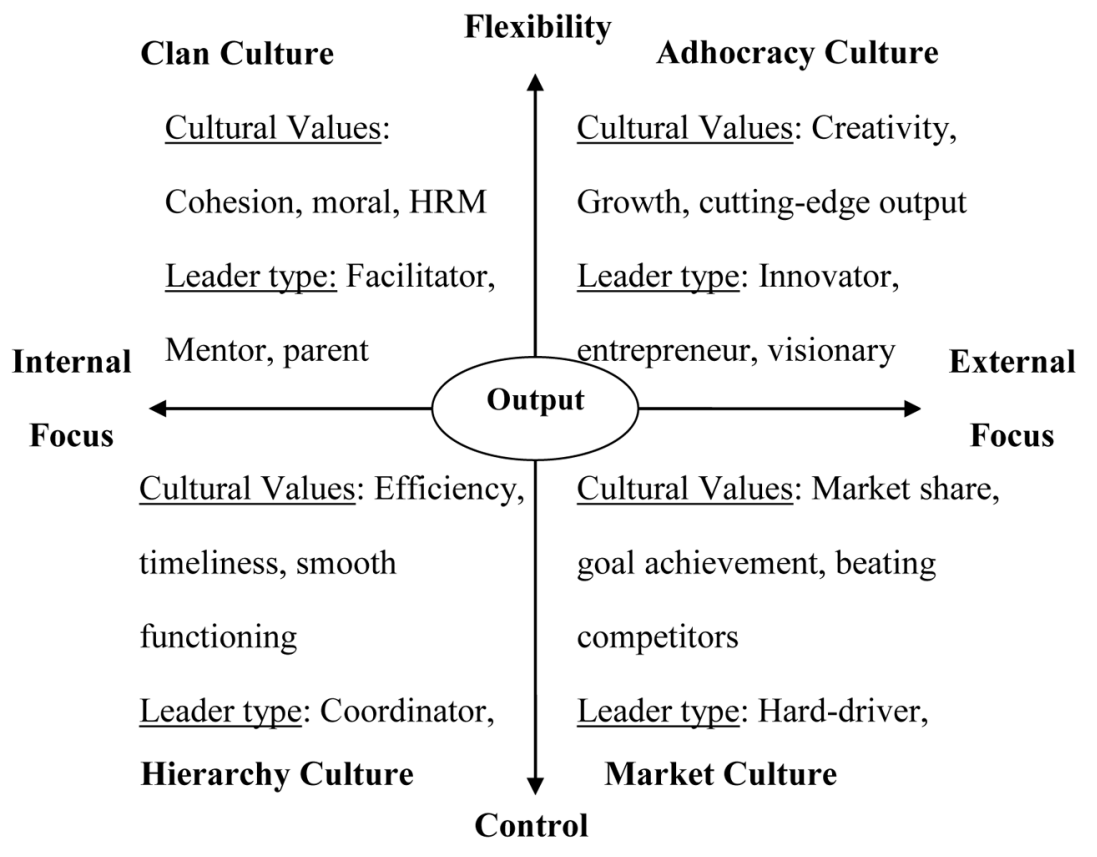

Figure 1 - The CVF of organizational culture. Note. Figure is adapted with permission from "Diagnosing and Changing Organizational Culture Based on the Competing Values Framework" (Cameron \& Quinn, 1999). Addison-Wesley Publishing Company, Inc. p. 32. 
representation of the current and desired culture profile (see Figure 1). Each continuum presents value creation and performance criteria that are opposite from the value creation and performance criteria on the other end of the continuum (Kwan $\&$ Walker, 2004). The dimensions, therefore, produce cultural types that can also be competing with cultural values. For instance, an extreme external focus on marketing may be effective to build a strong customer base, but could result in a reduced focus on employee relations and satisfaction. This could result in improved effectiveness in the externally focused marketing dimension and reduced effectiveness in the internal dimension of human relations.

The clan culture is internally focused and concerned with human relations. This cultural value is reflected in concerns for employee loyalty, commitment, and group cohesion. The adhocracy culture focuses on innovation, flexibility, and change designed to satisfy key external stakeholders. This orientation concentrates on growth, stimulation, creativity, and variety. The market culture values productivity, performance, goal fulfillment, and achievement. Traditionally, the purpose of organizations with an emphasis on the market culture tends to be the pursuit and attainment of well-defined objectives such as financial success. Finally, the hierarchy culture can be described as emphasizing internal efficiency, uniformity, coordination, and evaluation. For example, the focus is on the maintenance of the internal organization and the emphasis is on stability. The purpose of organizations with emphases on the hierarchy culture tends to be the execution of regulations. Motivating factors include security, order, rules, and regulation.

A cultural profile developed with the CVF provides a straightforward way to model the dynamic characteristics of organizational culture, which practitioners can use for diagnosis and intervention (Brown \& Dodd, 1998). Comparison of the current organizational profile with the ideal can identify imbalances and generate discussion concerning strategies for improvement and growth in each of the cultural types (Cameron \& Quinn, 1999). Survey feedback can also be transformed into an action research process based on the members clarifying what the desired culture means, the benefits, and the proposed changes to ensure the development of the desired culture (Kalliath, Bluedorn, \& Gillespie, 1999). According to Quinn and Cameron (1983), emphasizing only the values in a single quadrant could be dysfunctional. For example, too much flexibility or spontaneity could generate conflict in decision making processes, too much order and control could result in rigidity; an overemphasis on control and coordination could produce stagnation, loss of energy, and abolition of trust and morale. In other words, the strength of one quadrant may become a weakness for the organization, limiting its ability to satisfy other values. Consequently, constructing organizational culture profiles can be particularly relevant for understanding human resource management, quality initiatives, and planning and undertaking change and development.

\section{Organizational Culture Assessment Instrument (OCAI)}

Cameron and Quinn (1999) introduced the modified version of the instrument named OCAI based on the CVF. The questionnaire includes 24 items divided into four subscales labeled clan, adhocracy, market, and hierarchical. Each subscale has six items that address employee perceptions of core cultural elements such as 
dominant cultural type, leadership, management of employees, organizational glue, strategic emphases, and criteria of success (Shilbury \& Moore, 2006).

Several researchers have provided evidence for adequate reliability and validity of the OCAI in measuring organizational culture as well as its effectiveness in a variety of organizations (e.g., Cameron \& Freeman, 1991; Cameron \& Quinn, 1999; Colyer, 2000; Quinn \& Spreitzer, 1991). For instance, Quinn and Spreitzer (1991) reported a Cronbach's alpha coefficient of greater than .70 for each culture type in a sample of 800 participants from 86 different public utility firms. Yeung, Brockbank, and Ulrich (1991) studied over 10,000 business executives and found a Cronbach's alpha coefficient close to .80. Kalliath, Bluedorn, and Gillespie (1999) used structural equation modeling to test the factor structure of the OCAI (Quinn \& Spreitzer, 1991) and reported "excellent validity and reliability estimates" (p. 143). Colyer (2000) also reported moderate to high internal consistencies of the subscales as indicated by Cronbach's alphas that ranged from .58 to .88 . However, limited evidence for validity of the OCAI was presented in their studies. To date, no cross-cultural validity studies of the OCAI are available. This limited and insufficient validity evidence presents a serious concern for future research as we do not know if it is valid for different cultures.

\section{Validating a Translated Psychometric Scale}

The translated version of the OCAI has been used to measure organizational culture within various organizations by several foreign researchers. However, most of them did not appropriately address how each item in the OCAI was translated and what method was applied to validate its translated version. For instance, Kwan and Walker (2004) conducted research validating the OCAI using seven institutions in Hong Kong. Kim (2004) also used a translated version of the OCAI to investigate organizational culture differences between public and private sectors using 700 organizational members from 24 organizations in Korea. These studies did not provide adequate information about an item translation process that plays a significant role in validating a psychological instrument adapted from one language into another. Inappropriate translation processes often result in a biased, inconclusive, or misguided research outcomes (Maneesriwongul \& Dixon, 2004). Developing an acceptable instrument for another cultural group requires more effort than a literal translation, which all too often is the common practice (Usunier, 1998). There is a growing need for standard and validated practices for translating psychological instruments. Moreover, when an instrument is adapted to measure cultural values with a sample different from the original validation study, its psychometric properties, such as reliability and validity, have to be reexamined. To minimize the bias of interpreting a certain word from the original term, there should be a validation process confirming that the meaning of the original source is correctly conveyed and interpreted. Usunier (1998) claimed that to insure validity in the translation process, back-translation should be used to ensure that the target language is as near as possible to meaning in the original source language. Language is a significant predictor of cultural distance (West \& Graham, 1998); therefore, it is important for foreign researchers to validate the translated psychometric scale using the backtranslation technique. 
In the current study, we validated the Korean OCAI by establishing cultural equivalences and conducting a confirmatory factor analysis. The Korean Professional Baseball League (KPBL) was selected for the following reasons; According to Kim (2004), most public organizations in South Korea are characterized by the hierarchy culture as a dominant culture type. The study conducted by Choi (2005) reported that business and public organizations had strong cultural emphases on both the market and hierarchy culture. Because of the growth in the sport industry in Korea and the popularity of professional baseball, it was determined that the KPBL might offer valuable insights into how the cultural values and types proposed by the CVF were embodied within these organizations. Although sport managers, practitioners, and administrators within the KPBL have recently recognized problems in managing organizational culture, little is known about the outcomes of creating, managing, and changing organizational culture (Choi, 2005; Kim, 2004). Moreover, there has been little effort to analyze specific dimensions of organizational culture within sport organizations in the Korean sport industry, and no single instrument to measure variables has been developed. Therefore, it was deemed necessary to translate the English version of the OCAI (Cameron \& Quinn, 1999) into Korean to quantitatively examine organizational culture in Korean professional baseball organizations. This study is a first step toward establishing a valid Korean version of the CVF.

\section{Purpose of the Study}

Two studies were conducted to test the validation of a Korean OCAI. The purpose of Study 1 was to examine the psychometric properties of the Korean version of the OCAI. Study 1 also aimed to establish cultural equivalences including content, semantic, and administration of survey for validating the Korean version of the OCAI. The objective of Study 2 was to develop a reliable organizational culture scale by conducting a confirmatory factor analysis using 133 organizational members from the KPBL.

\section{Study 1: Cultural Equivalence}

In this section, we developed the Korean version of the OCAI and established cultural equivalence between the Korean version and the original English version. In cross-cultural management, three common types of equivalence have been identified for cross-cultural research through literature reviews (Flaherty, et al., 1988; Schaffer \& Riordan, 2003; Usunier, 1998). The three types are content, semantic, and survey administration. The psychometric properties of two versions were examined using 39 bilingual students.

\section{Content Equivalence}

In cross-cultural research, content equivalence should be established by determining whether the content of each item of the instrument used has a similar meaning across the social cultures (Usunier, 1998). In establishing content equivalence, a panel of content experts evaluated each item. For the current study, the questionnaire was submitted to a panel of four academicians called "American Content Experts" who are recognized authorities in the field of sport management. The American 
experts were four faculty members in sport management programs at two higher educational institutions in the United States. The American experts evaluated each item of the original OCAI based on the underlying construct. They concluded that all 24 items in the original OCAI were appropriate to measure organizational culture within sport organizations.

Furthermore, a panel of three Korean academicians called "Korean Content Experts" was invited to evaluate a Korean version. The Korean experts were professors in sport management at three different universities recognized by the Korean Society for Sport Management (KSSM). Of the 24 items in the Korean version questionnaire, 20 items were identified as being well translated for Korean sport organizational members. However, the Korean experts noted that four items (item $\# 13,14,15, \& 16$ ) were culturally unacceptable because some words in those items could not be directly equated to items in the original questionnaire. For example, "organizational glue" conveys different meanings in Korean compared with English. The items measuring "organizational glue" from the original OCAI were modified based on the Korean panel's recommendations and suggestions. We selected the appropriate Korean word for the meaning of cohesion for the items instead of using the original word. Then, the modified items were included in subsequent analysis after conducting a back-translation technique, which is described next.

\section{Semantic Equivalence}

The essence of semantic equivalence is that the meaning of each item remains the same after translation into the target language (Flaherty et al., 1988). For establishing semantic equivalence, the most common and highly recommended procedure is the back-translation approach (Schaffer \& Riordan, 2003). After translating the original questionnaire into Korean by two sport management scholars and the principal investigator, a back-translation technique was employed to identify possible translation errors. First, the translation committee evaluated the Korean version as to whether each item conveyed the same meaning as the original version. The translation committee included the principal investigator and two bilingual doctoral students from the English department. Second, the Korean version was back-translated into English by the other bilingual doctoral student. This back-translator compared the original English items and the back-translated English items to determine whether the translation was performed appropriately. The back-translator evaluated and rated each item on a 3-point scale, for which $3=$ exactly the same meaning in both versions, $2=$ almost the same meaning, and $1=$ different meaning in each version. All the 24 items were in an acceptable range, which means that the back-translator gave at least a score of 2 or more on each item. To avoid any bias during the process, the back-translator did not participate in the previous translation process.

\section{Administration of Survey}

The third aspect of establishing cultural equivalence is whether the administration of surveys is consistent across different social contexts. Procedurally, there should be consistency across samples in terms of survey formats, data collection, survey timing, and survey setting (Flaherty et al., 1988; Usunier, 1999). In this study, the paper and pencil method was used to administer the OCAI so that the results 
were not affected by the method of data collection. To minimize methodological errors from the administration of the survey, the original version of the OCAI was first given to the participants, and then after completing the English version of the instrument, the Korean version of the OCAI was distributed.

\section{Psychometric Properties}

After completing the translation of the instrument, cultural appropriateness was determined, and instrumental discrepancies between the original and translated instruments were resolved. Then, bilingual field testing was performed using both the original and translated instruments with a bilingual group. An important issue in cross-cultural research is the consideration of whether cross-cultural samples are comparable across countries (Schaffer \& Riordan, 2003).

Sample. To minimize the negative effects of sampling difference, a convenience sample of 39 bilingual graduate students who read and understand both English and Korean was selected from four higher educational institutions in the United States. The criteria for selection included length (at least three year) of living in the U.S., academic status (at least a graduate student at higher educational institution), and Korean citizen. Of the 39 respondents in the study, $46.2 \%$ were female and $53.8 \%$ were male. Respondents' age ranged from 25 to 36 years with average age of 31 years. Forty seven percent were master degree students and $53 \%$ were doctoral students. The average length of living in the U.S. was 4.5 years.

Measurement. Cultural strength and type were measured by the English and Korean versions of the OCAI, which was composed of a total of 24 items with a 6-point Likert-like scale. The scale ranged from 1 (strongly disagree) to 6 (strongly agree) with participants rating the extent to which they agree with each statement. With the 6-point scale, scores range from 24 to 144, with a higher score indicating a higher level of strength of that type of organizational culture.

Procedures. The instruments were assembled into packets with the English version first and Korean version second. Because the participants were less familiar with the English version of the OCAI, we predicted it would be less likely to influence their responses to items on the Korean version. The participants completed the English and Korean versions of the OCAI without any time lapse between the measures, and participants were asked not to discuss the items with each other.

Data Analysis. If items measure the same content, there should be no withinsubject variance between the two languages; therefore, the items would have similar means, standard deviations, and psychometric properties for the Korean and English versions. To evaluate whether the items in each version were scored similarly, a paired $t$ test for each item and correlation analysis using the Statistical Package for Social Science (2005) were employed.

\section{Scale Reliability}

Cronbach's alpha (Cronbach, 1951) coefficients were calculated to examine the reliability of the scales. Tables 1 and 2 contain the results from the reliability 
Table 1 Reliability Coefficient for Each Cultural Scale with English Version of the OCAI

\begin{tabular}{lccccc}
\hline & Clan & Adhocracy & Market & Hierarchy & $\begin{array}{c}\text { Cronbach's } \\
\alpha\end{array}$ \\
\hline Clan & 1.000 & & & & .79 \\
Adhocracy & $.633^{* *}$ & 1.000 & & & .89 \\
Market & $.395^{*}$ & $.733^{* *}$ & 1.000 & & .92 \\
Hierarchy & $.690^{* *}$ & $.758^{* *}$ & $.835^{* *}$ & 1.000 & .84 \\
\hline
\end{tabular}

Note: $* p<.05,{ }^{* *} p<.01$.

Table 2 Reliability Coefficient for Each Cultural Scale with Korean Version of the OCAI

\begin{tabular}{lccccc}
\hline & Clan & Adhocracy & Market & Hierarchy & $\begin{array}{c}\text { Cronbach's } \\
\alpha\end{array}$ \\
\hline Clan & 1.000 & & & & .78 \\
Adhocracy & $.727 * *$ & 1.000 & & & .88 \\
Market & $.464 * *$ & $.788^{* *}$ & 1.000 & & .92 \\
Hierarchy & $.570^{* *}$ & $.779 * *$ & $.878^{* *}$ & 1.000 & .87 \\
\hline
\end{tabular}

Note: ${ }^{* *} p<.01$.

analysis including intercorrelations for the four cultural types for both versions of the instrument. The reliability coefficient alpha for the English version of the OCAI ranged from .79 to .92 and from .78 to .92 for the Korean version of the same measure. The reliability analysis indicated that the deletion of any items would not substantially increase the value of Cronbach's alpha (Cronbach, 1951) for both versions of the instrument. According to the results of the correlation analysis, there was a strong relationship ( $r=.84$ English $\& r=.88$ Korean) between market and hierarchy cultures in the two versions of the instrument.

\section{Results}

Paired $t$ tests and Pearson's correlations between each of the original 24 items and the Korean version of the same items were examined to determine estimates of construct validity. Table 3 shows the results of the paired $t$ test for the paired items. There were no significant mean differences among the English and Korean items at the significant level of .05. These results indicate that all items in the English version of the questionnaire were appropriately translated into Korean after conducting the back-translation technique. Table 4 presents the results of Pearson's correlation for the paired items. Pearson's correlations demonstrated that all items of the OCAI had significant correlations $(r=.43-.90, p<.05)$ between the original English version and the Korean version of the OCAI. Overall, none of the items would be regarded as having unacceptable numeric properties. 
Table 3 Paired t Test for Paired Items $(N=39)$

\begin{tabular}{|c|c|c|c|c|c|}
\hline \multicolumn{2}{|c|}{ Variable } & \multicolumn{2}{|c|}{$M$} & \multirow[t]{2}{*}{$t$} & \multirow[t]{2}{*}{$p$} \\
\hline & & Korean & English & & \\
\hline Pair 1 & (Q1) & 3.9487 & 3.8462 & .752 & .457 \\
\hline Pair 2 & (Q2) & 3.6667 & 3.6667 & .000 & 1.00 \\
\hline Pair 3 & (Q3) & 4.0513 & 4.3077 & -1.96 & .058 \\
\hline Pair 4 & (Q4) & 4.0256 & 4.1538 & -.961 & .342 \\
\hline Pair 5 & (Q5) & 4.1026 & 4.3077 & -1.43 & .160 \\
\hline Pair 6 & (Q6) & 4.0513 & 3.8462 & 1.54 & .132 \\
\hline Pair 7 & (Q7) & 3.8462 & 3.9744 & -.842 & .405 \\
\hline Pair 8 & (Q8) & 4.6410 & 4.7436 & -.681 & .500 \\
\hline Pair 9 & (Q9) & 4.5385 & 4.6154 & -.650 & .520 \\
\hline Pair 10 & (Q10) & 3.8974 & 4.0000 & -.781 & .440 \\
\hline Pair 11 & (Q11) & 3.9744 & 3.8974 & .408 & .686 \\
\hline Pair 12 & (Q12) & 3.9487 & 3.6923 & 1.61 & .115 \\
\hline Pair 13 & (Q13) & 4.3333 & 4.1795 & .734 & .467 \\
\hline Pair 14 & (Q14) & 4.1282 & 3.9744 & .784 & .438 \\
\hline Pair 15 & (Q15) & 4.1282 & 4.1538 & -.154 & .878 \\
\hline Pair 16 & (Q16) & 4.0256 & 4.3077 & -1.72 & .094 \\
\hline Pair 17 & (Q17) & 4.0000 & 4.2564 & -1.82 & .077 \\
\hline Pair 18 & (Q18) & 4.0513 & 4.0256 & .227 & .822 \\
\hline Pair 19 & (Q19) & 4.0513 & 4.1282 & -.771 & .446 \\
\hline Pair 20 & (Q20) & 4.3077 & 4.3590 & -.321 & .750 \\
\hline Pair 21 & (Q21) & 4.3333 & 4.4359 & -.628 & .534 \\
\hline Pair 22 & (Q22) & 4.0000 & 3.7692 & 1.942 & .060 \\
\hline Pair 23 & (Q23) & 4.0513 & 3.8718 & 1.096 & .280 \\
\hline Pair 24 & (Q24) & 4.0769 & 4.0769 & .000 & 1.00 \\
\hline
\end{tabular}

Note. $\mathrm{Q}=$ Item in the questionnaire of the OCAI.

$* p<.05$.

\section{Study 2: A Field Test for the Korean Version of the OCAI}

Despite extensive use of the OCAI in business management, only a few researchers (e.g., Colyer, 2000; Shilbury \& Moore, 2006) in the field of sport management have adapted the instruments. It is necessary to retest psychometric properties when a psychological measurement scale is adapted with a sample different from the original validation study. The primary purpose of Study 2 was to examine the reliability and construct validity of the Korean version by conducting a field test using 133 organizational members from the KPBL. A confirmatory factor analysis was conducted to achieve that purpose. 
Table 4 Correlation for Paired Items $(N=39)$

\begin{tabular}{llll}
\hline & Variable & $\boldsymbol{N}$ & Pearson's $\boldsymbol{r}$ \\
\hline Pair 1 & $(\mathrm{Q} 1)$ & 39 & $.776^{* *}$ \\
Pair 2 & $(\mathrm{Q} 2)$ & 39 & $.842^{* *}$ \\
Pair 3 & $(\mathrm{Q} 3)$ & 39 & $.811^{* *}$ \\
Pair 4 & $(\mathrm{Q} 4)$ & 39 & $.786^{* *}$ \\
Pair 5 & $(\mathrm{Q} 5)$ & 39 & $.692^{* *}$ \\
Pair 6 & 39 & $.829^{* *}$ \\
Pair 7 & $(\mathrm{Q} 6)$ & 39 & $.786^{* *}$ \\
Pair 8 & $(\mathrm{Q} 7)$ & 39 & $.639^{* *}$ \\
Pair 9 & $(\mathrm{Q} 8)$ & 39 & $.799^{* *}$ \\
Pair 10 & $(\mathrm{Q} 9)$ & 39 & $.809 * *$ \\
Pair 11 & $(\mathrm{Q} 10)$ & 39 & $.590^{* *}$ \\
Pair 12 & $(\mathrm{Q} 11)$ & 39 & $.690^{* *}$ \\
Pair 13 & $(\mathrm{Q} 12)$ & 39 & $.426^{* *}$ \\
Pair 14 & $(\mathrm{Q} 13)$ & 39 & $.469^{* *}$ \\
Pair 15 & $(\mathrm{Q} 14)$ & 39 & $.723^{* *}$ \\
Pair 16 & $(\mathrm{Q} 15)$ & 39 & $.642^{* *}$ \\
Pair 17 & 39 & $.673^{* *}$ \\
Pair 18 & $(\mathrm{Q} 16)$ & $.792^{* *}$ \\
Pair 19 & $(\mathrm{Q} 17)$ & 39 & $.904^{* *}$ \\
Pair 20 & $(\mathrm{Q} 18)$ & 39 & $.618^{* *}$ \\
Pair 21 & $(\mathrm{Q} 19)$ & 39 & $.877^{* *}$ \\
Pair 22 & $(\mathrm{Q} 20)$ & $39 * *$ \\
Pair 23 & $(\mathrm{Q} 21)$ & 39 & $.666^{* *}$ \\
Pair 24 & $(\mathrm{Q} 22)$ & 39 & \\
\hline
\end{tabular}

Note. $\mathrm{Q}=$ Item in the questionnaire of the OCAI.

$* * p<.01$.

\section{Sample}

Participants were 133 employees in the eight professional baseball organizations within the KPBL. A total of 277 questionnaires were mailed out to staff and management personnel from the selected professional baseball organizations in the KPBL. A total of 133 questionnaires from eight professional baseball organizations in KPBL were received, accounting for a final overall response rate of $48 \%$. All these 133 participants were full-time employees and had at least one year of experience in the KPBL. The largest group was front office staff $(80.5 \%)$ followed by managers $(10.5 \%)$ in the KPBL. The respondents were comprised of $83.5 \%$ male and $16.5 \%$ female. The years of employment with the organizations ranged from 1 year to 27 years $(M=7.01, S D=5.49)$. 


\section{Instrument and Procedures}

The Korean version of the OCAI was used to test its applicability and validation in the field of sport management in Korea. Packets with Korean OCAI were mailed to the eight professional baseball organizations from the KPBL. Instructions asked participants to rate their perceptions of organizational culture within their respective professional baseball clubs.

\section{Data Analysis}

Cronbach's alpha (Cronbach, 1951) coefficient was used to examine the internal reliability and a Confirmation Factor Analysis (CFA) using LISREL 8.52 (Jöreskog \& Sörborn, 2001) was employed to examine the factor structure of the Korean version of the OCAI. By using Structural Equation Modeling (SEM), we specified the number of latent constructs as well as their corresponding items in a model. Based on Cameron and Freeman's (1991) model, three restrictions were applied in SEM. First, each of the cultural types was viewed as latent constructs with the appropriate six items loading on each. Second, correlations were allowed between adjacent latent constructs: between clan and adhocracy, between adhocracy and market, between market and hierarchy, between hierarchy and clan. Third, no statistically significant relationship between cultural types located in the two opposite quadrants (i.e., between clan and market and between adhocracy and hierarchy) was specified.

According to Muthén and Kaplan (1985), Maximum Likelihood (ML) function is quite robust for observed categorical variables with skewnesses and kurtoses from -1.0 and +1.0 . Because the observed categorical variables were close to normal with relatively small skewnesses and kurtoses (less than \pm 0.5 ), the ML method was employed for estimation. The loading of all manifest factors onto a latent construct termed cultural value types was performed. The fit of the hypothesized four cultural factor model to the data were examined with several fit indices including Root Mean-square Residual (RMR), chi-square $\left(\chi^{2}\right)$, Goodness of Fit Index (GFI), Root Mean Square of approximation (RMSEA) and Normed Fit Index (NFI). For a good model data fit, all residuals should be close to zero indicating that the sample covariance matrix of the observed variables corresponds to the implied matrix by the model. The sample size for the study is relatively small to generalize the findings of the study. However, the number of participants for the study well represents the population of entire official front staff $(N=277)$ in the KPBL. In addition, according to Bollen (1989), samples of at least 100 subjects are adequate when latent variables have only three indicators and we had six per variable.

\section{Results}

The reliability coefficient for the four cultural types ranged from .76 to .85 . The Clan type (.85) showed the highest reliability followed by the Adhocracy (.84). The correlation between clan and adhocracy had the strongest relationship $(r=.84, p$ $<.01)$ among all the pairs of the cultural types.

Specifying the three restrictions, the model showed a moderate fit $(\mathrm{RMR}=.09$; $\chi^{2}=373.94, d f=246, p<.01 ; \mathrm{GFI}=.64 ; \mathrm{RMSEA}=.06$; NFI $\left.=.94\right)$. The overall model fit described above is based on the difference between the observed sample covariance matrix and the implied covariance matrix of the model. Considering our values, the model provided a moderate fit because RMSEA was less than .10 and 
the NFI was higher than .90. Specifically, item 1 showed a poor fit in the model by having relatively high measurement error as well as small coefficient relating item 1 to the clan factor. Table 5 shows the squared multiple correlations $\left(R^{2} s\right)$ for each item. The $R^{2}$ indicates the proportion of variance in each item explained by its corresponding latent variable (Bollen, 1989). Every item in the proposed model has no direct effect from other variables except its corresponding factor. Thus, the unique validity variance for each item that is solely attributable to its corresponding latent variable is the same as the $R^{2}$ for each item. As seen in Table $5, R^{2}$ s for the six items measuring the clan culture ranged from .41 to .56 except item 1 , those for adhocracy ranged from .35 to .73 , those for the market items ranged from .41 to .60 , and those for the hierarchy culture ranged from .30 to .59 . We tested an alternative model excluding item 1, but maintaining the same specifications and then tested the chi-square of the difference between two models. However, there was no significant statistical difference between the two models.

Figure 2 shows statistically significant positive correlations between all paired cultural types. As hypothesized, the relationships of the four pairs of the adjacent cultural types were all positive and ranged from .70 to .96 . The strongest relationship was shown between adhocracy and market $(r=.96, p<.05)$ followed by the relationship between clan and adhocracy $(r=.92, p<.05)$. On the other hand, the hypothesized zero correlations between clan and market and between adhocracy and hierarchy showed unexpected results. The data indicated that the relationship between clan and market was very strong $(r=.89, p<.05)$. The relationship between adhocracy and hierarchy was moderate, but statistically significant $(r=.52, p<$ $.05)$. These results are discussed in the following section.

\section{Discussion}

The purpose of this study was to examine the psychometric properties of the newly developed Korean OCAI. The Korean translation version of the original English OCAI showed acceptable psychometric properties. The decision criteria for psychometric equivalence were made by three rationales (content, semantic, and administration of survey) and two statistical analyses: a paired $t$ test and Pearson's correlations. From the first criteria, all items of the Korean version of the OCAI had acceptable agreement score by the back-translator. From the paired $t$ test, all items demonstrated no significant mean differences between the Korean version and

\section{Table 5 Squared Multiple Correlations for the Observed Variables}

\begin{tabular}{cccccccc}
\hline \multicolumn{7}{c}{ Corresponding Factors (Cultural Types) } \\
\hline \multicolumn{2}{c}{ Clan } & \multicolumn{2}{c}{ Adhocracy } & \multicolumn{2}{c}{ Market } & \multicolumn{2}{c}{ Hierarchy } \\
\hline Item \# & $\boldsymbol{R 2}$ & Item \# & $\mathbf{R 2}$ & Item \# & $\mathbf{R 2}$ & Item \# & $\mathbf{R 2}$ \\
\hline 1 & 0.01 & 2 & 0.49 & 3 & 0.40 & 4 & 0.32 \\
5 & 0.41 & 6 & 0.35 & 7 & 0.58 & 8 & 0.34 \\
9 & 0.54 & 10 & 0.67 & 11 & 0.41 & 12 & 0.59 \\
13 & 0.53 & 14 & 0.64 & 15 & 0.58 & 16 & 0.51 \\
17 & 0.56 & 18 & 0.73 & 19 & 0.60 & 20 & 0.54 \\
21 & 0.49 & 22 & 0.38 & 23 & 0.43 & 24 & 0.30 \\
\hline
\end{tabular}



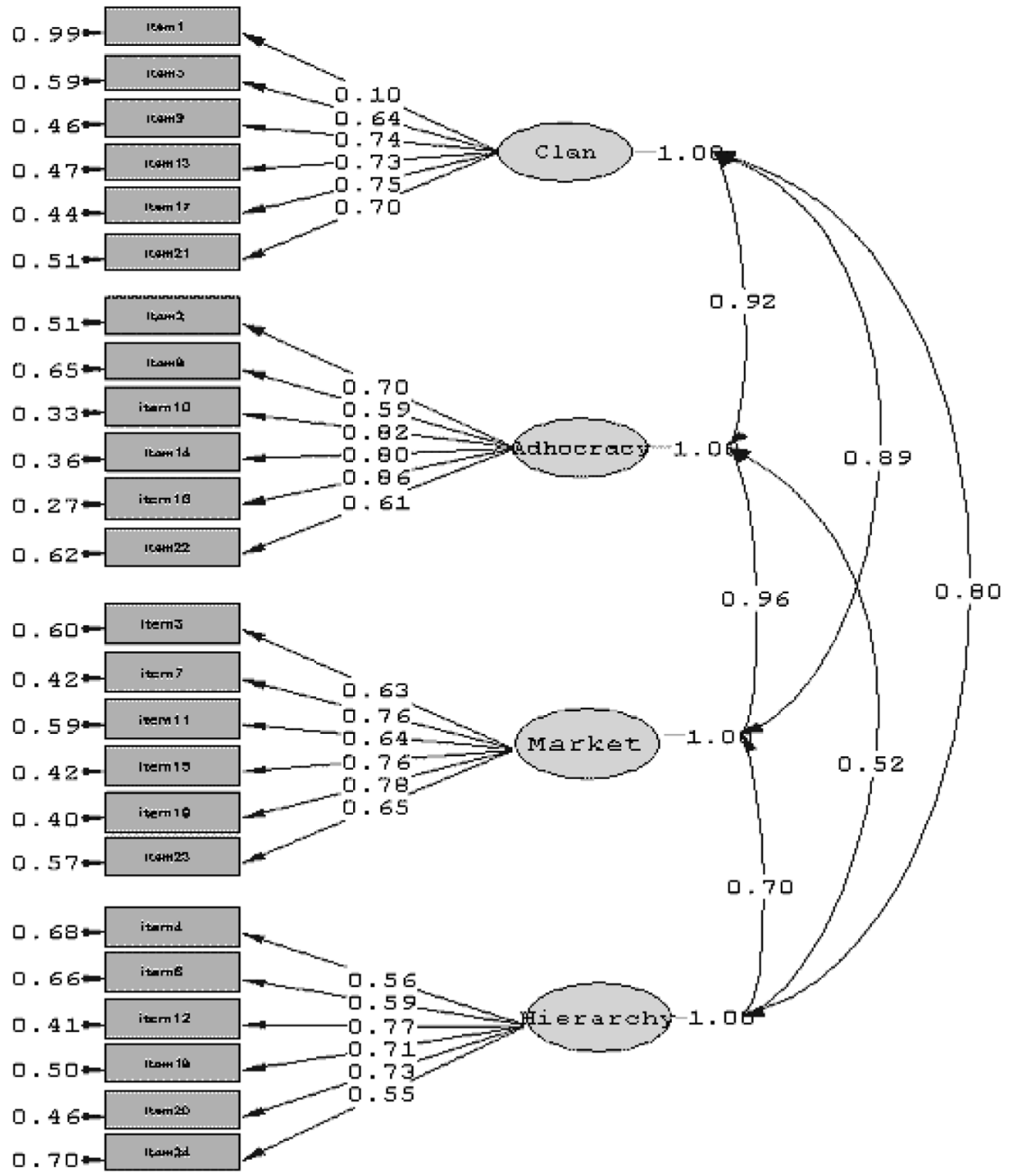

Figure 2 - Results of a structural equation test of the CVF of organizational culture. Note. The numbers shown in the diagram, from left to right, are as follows; (a) standardized error term, (b) validity coefficient, (c) correlation between latent constructs.

original English versions of the OCAI. Finally, Pearson's correlations showed that all items of the OCAI had significant correlations $(r=.43-.90, p<.05)$ between the original English version and the Korean version of the OCAI. The reliability coefficient for the four cultural types subscales ranged from .78 to .92 with the Korean version of the OCAI while the English version generated reliability coefficients ranging from .79 to .92 . Overall, none of the items would be regarded as having unacceptable numeric properties by the three decision criteria. Based on translation, back-translation, and bilingual field tests, the Korean version of the 
OCAI appears to have strong construct validity and reliability for use in measuring organizational culture within a Korean sport organization.

Based on the panel's suggestion, items 13, 14, 15, and 16 (Organizational glue) were modified to better reflect Korean language and then included in subsequent analysis after the back-translation process. Technically, back translation technique helps to identify probable translation errors. This particular part of the validation process in terms of back-translation ensures that the translated scale reflects a semantic consistency. In this study, the word "glue" might be interpreted as "sticky" or "gum" in Korean, so, when an original word contains two meanings, it might be conveyed and interpreted in different ways. Misinterpretation of a word used in an original psychological instrument might generate a biased findings or methodological error negatively impacting the results of the data analysis.

Although there is previous evidence to support the OCAI using multitraitmultimethod analysis and multidimensional scaling (Quinn \& Spreitzer, 1991), the current study added a third methodology, confirmatory factor analysis. The results of the CFA used in this study indicated a moderate fit. Items 1 and 2 showed a poor fit with relatively high measurement error as well as small coefficient relating to clan culture. However, a simple solution of excluding one of those items or both did not provide any improvement in terms of overall model fit. It is not clear whether this discrepancy is due to a different sample from where the OCAI was originally developed. Further research is needed to investigate this difference. On the one hand, as hypothesized, adjacent cultural types had positive and strong relationship. On the other hand, the hypothesized zero correlations between clan and market and between adhocracy and hierarchy were not supported. However, several reasons may explain this unexpected finding. Although the organizations in the KPBL appear to emphasize the market and hierarchy cultures as a dominant cultural type, the KPBL demonstrated evidence of reasonable balance in all four cultural types (see Figure 3). Because of the dynamic market condition including the fan base, degree

Flexibility

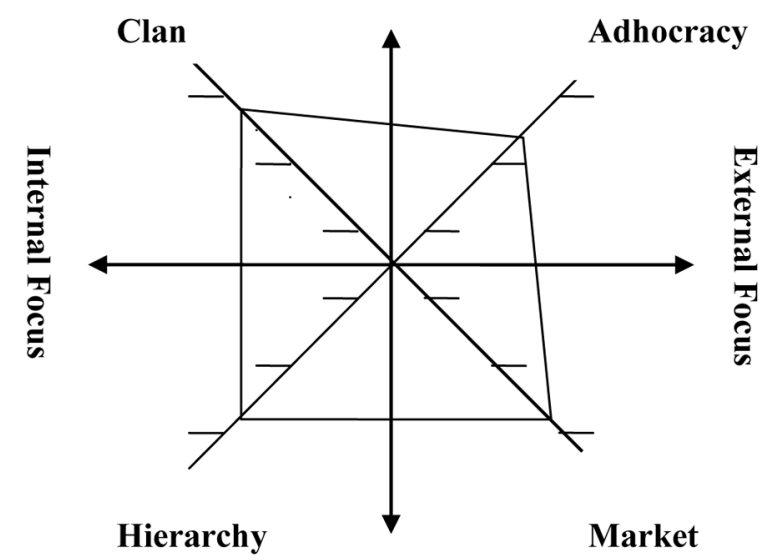

Stability

Figure 3 - Cultural archetype of the KPBL. 
of market competition, and geographic location in the sport industry, the professional baseball organizations in the KPBL have established various business objectives to achieve their organizational goals. In other words, sport organizations in the Korean sport industry have emphasized multiple cultural values such as internal integration, innovation, and technological adaptation. Many sport organizations such as the ones we studied become proactive and professional in response to anticipated changes in their environment. Amis, Slack, and Hinings (2004) pointed out that within the sport industry, technological advancement and greater competition in the market place have forced most sport organizations to change internal and external environments to contribute to organizational goals and business objectives. The possibility of organizations emphasizing multiple effectiveness criteria, including such apparently contradictory factors as the internal process and open systems, is a paradox inherent in the CVF and one of the framework's greatest strengths. This indicates that cultural balance has been achieved by these organizations. While there were slight differences in employees' perceptions of the organizational culture from representative organizations in the league, we determined that the market and hierarchy cultures were perceived to be stronger in the KPBL. Consequently, maintaining the balance of cultural strength in four cultural types might help sport organizations be more competitive and achieve organizational success. However, these unexpected relationships could be explained by a coexisting culture in a sport field. For further investigation, a study about the structure of the cultural type in American professional baseball is in process.

Because, to our knowledge, no previous researchers have reported organizational culture in the Korean population as well as Korean American populations, this translated OCAI could be very useful for researchers interested in examining organizational culture in the Korean sport sector. For instance, the OCAI provides a tool that Korean sport organizations may use to define a current profile of their organizational culture for organizational diagnosis (Colyer, 2000). Furthermore, a research inquiry to determine differences and similarities between organizational members' current and desired perceptions of organizational culture can also be conducted. In addition to the application and applicability of the Korean version of the OCAI, Korean sport organizations may use this particular measurement scale to identify the types and levels of cultural conflicts involved in a decisionmaking process. As Cameron and Quinn (1999) suggested, identifying which cultural types are present and the extent to which they are emphasized should be considered as an earlier step than forcing congruence and consistency. Therefore, other possible research inquiries for the population of Korean sport organizations with this translated measurement scale can be found in many ways: (a) comparing cultural types in the two market segments to examine the different cultural context of two countries or more, (b) determining if there are differences in perceptions of cultural strength across the four cultural types within the collective sample from each country, and (c) defining which cultural type in the CVF is dominant within each sport organization as well as each market segment.

According to Scott (1997), cultures can be managed and changed, but the question of how much change in culture can be planned for and implemented by existing or new management is still unanswered. However, organizations may experience success in cultural change and management only when that change is in the direction of greater congruence with the demands of the industry and not when it is in conflict with basic assumptions. The Korean sport industry might have 
unique cultures in terms of intensity of market competition, environment, value, and system. It might be necessary for these sport organizations to pursue their long-term business goals by identifying the rapid change of cultural values playing a significant role in the management process. Hence, Korean sport organizations may be able to establish scenarios, develop alternatives and formulate contingency strategies for a future organizational development with the newly developed Korean version of the OCAI. In this way, they will be able to anticipate and respond to organizational culture changes effectively.

In conclusion, the statistical analysis indicates that the Korean version of the OCAI showed acceptable psychometric properties. However, further psychometric testing in larger samples using various sport organizations is needed to establish further reliability and validity. In addition, it appears that the CVF, for analyzing organizational culture, is very applicable to professional baseball clubs and may apply to other sport organizations as well. The findings of the current study might also help direct organizational culture in professional baseball organizations. As indicated by Slack and Parent (2006), sport organizations operating with stable cultures seek internal support rather than adapting to the external environment. Furthermore, Skinner, Stewart, and Edwards (1999) reported that sport organizations tend to enforce traditional roots including vision, story, myth, and symbol rather than being adaptable to changing circumstances. However, because of the growth of professionalism and increased commercialization in the sport industry, understanding organizational culture may provide sport organizations with a way to successfully deal with that culture. There should be further investigations of organizational culture in sport organizations to determine how to best enhance their organizational effectiveness.

\section{References}

Amis, J., \& Slack, T. (2002). Values of organizational change. The Journal of Applied Behavioral Science, 38, 436-465.

Amis, J., Slack, T., \& Hinings, C.R. (2004). strategic change and the role of interests, power and organizational capacity. Journal of Sport Management, 18, 158-198.

Bollen, K.A. (1989). Structural equations with latent variables. New York: John Wiley \& Sons.

Brown, F.W., \& Dodd, N.G. (1998). Utilizing organizational culture gap analysis to determine human resource development needs. Leadership and Organization Development Journal, 19, 374-385.

Cameron, K.S., \& Freeman, S.J. (1991). Cultural congruence, strength, and type: Relationships to effectiveness. Research in Organizational Change and Development, 5, 23-58.

Cameron, K.S., \& Quinn, R.E. (1999). Diagnosing and changing organizational culture Based on the competing values framework. Reading, MA: Addison-Wesley.

Champoux, J.E. (1996). Organizational behavior: Integrating individuals, groups, and processes. St. Paul, MN: West Publishing Company.

Choi, S. (2005). The study of organizational culture profile in Korean administrative organizations. Korean Journal of Public Administration, 39(2), 41-62.

Colyer, S. (2000). Organizational culture in selected western Australian sport organizations. Journal of Sport Management, 14, 321-341.

Cooke, R., \& Lafferty, J. (1989). Organizational Culture Inventory (OCI). Plymouth, MI: Human Synergistics.

Cronbach, L.J. (1951). Coefficient alpha and the internal structure of tests. Psychometrika, 16, 296-334. 
Deal, T.E., \& Kennedy, A.A. (1988). Corporate culture: the rights and rituals of corporate life. Reading, MA: Addison-Wesley.

Delobbe, N., Haccoun, R.R., \& Vandenberghe, C. (2000). Measuring core dimensions of organizational culture: a review of research and development of a new instrument. Paper presented at the Annual Conference of the Society of Industrial and Organizational Psychology, Toronto, Canada.

Denison, R.D., \& Spreitzer, G.M. (1991). Organizational culture and organizational development: A competing values approach. Research in Organizational Change and Development, 5, 1-21.

Doherty, A.J., \& Chelladurai, P. (1999). Managing cultural diversity in sport organizations: A theoretical perspective. Journal of Sport Management, 13, 280-297.

Flaherty, J.A., Gaviria, M., Pathak, D., Mitchell, T., Wintrob, R., Richman, J., et al. (1988). Developing instruments for cross-cultural psychiatric research. The Journal of Nervous and Mental Disease, 17, 257-263.

Howard, L.W. (1998). Validating the competing values model as a representation of organizational cultures. The International Journal of Organizational Analysis, 6, 231-250.

Jöreskog, K.G., \& Sörbom, D. (2001). LISREL 8.52. Mooresville, IN: Scientific Software.

Kalliath, T.J., Bluedorn, A.C., \& Gillespie, D.F. (1999). A confirmatory factor analysis of the competing values instrument. Educational and Psychological Measurement, 59, $143-158$.

Kim, H. (2004). The comparison of organizational culture between administrative and business organizations in Korea. Korean Journal of Public Administration, 38(3), 49-67.

Kwan, P., \& Walker, A. (2004). Validating the competing values models as a representation of organizational culture through inter-institutional comparisons. The International Journal of Organizational Analysis, 12, 21-37.

Litwin, G., \& Stringer, R. (1968). Motivation and organizational climate. Cambridge, MA: Harvard University Press.

Lund, D.B. (2003). Organizational culture and job satisfaction. Journal of Business and Industrial Marketing, 18, 219-236.

Maneesriwongul, W., \& Dixon, J.K. (2004). Instrument translation process: A methods review. Journal of Advanced Nursing, 48, 175-186.

McShane, S.L., \& Glinow, M.A.V. (2000). Organizational Behavior. New York: McGrawHill.

Muthén, B., \& Kaplan, D. (1985). A comparison of some methodologies for the factor analysis of non-normal Likert variables. The British Journal of Mathematical and Statistical Psychology, 38, 171-189.

Ogbonna, E., \& Harris, L.C. (2002). Organizational culture: A ten year, two-phase study of change in the UK food retailing sector. Journal of Management Studies, 39, 673-706.

O'Reilly, C., Chatman, J., \& Caldwell, D. (1991). People, jobs, and organizational culture. Academy of Management Journal, 34, 487-516.

Papadimitriou, D., \& Taylor, P. (2000). Organizational effectiveness of Hellenic national sport organizations: A multiple constituency approach. Sport Management Review, 3, $23-46$.

Paparone, C.R. (2003). Applying the competing values framework to study organizational subcultures and system-wide planning efforts in a military University. Unpublished Doctoral Dissertation. The Pennsylvania State University, Middletown, PA.

Quinn, R.E., \& Cameron, K.S. (1983). Organizational life cycles and shifting criteria of effectiveness: Some preliminary evidence. Management Science, 29, 33-51.

Quinn, R.E., Faerman, S.R., Thompson, M.P., \& McGrath, M.R. (1990). Becoming a master manager: A competency framework. New York: John Wiley \& Sons. 28, 213-232.

Quinn, R.E., \& Rohrbaugh, J. (1981). A competing values approach to organizational effectiveness. Public Productivity Review, 5, 122-140.

Quinn, R.E., \& Rohrbaugh, J. (1983). A spatial model of effectiveness criteria: Towards a competing values approach to organizational analysis. Management Science, 29, 363-377. 
Quinn, R.E., \& Spreitzer, G.M. (1991). The psychometrics of the competing values culture instrument and an analysis of the impact of organizational culture on quality of life. Research in Organizational Change and Development, 5, 1-21.

Schaffer, B.S., \& Riordan, C.M. (2003). A review of cross-cultural mythologies for organizational research: A best-practices approach. Organizational Research Methods, 6, $169-215$.

Schein, E.H. (1992). Organizational culture and leadership (2nd ed.). San Francisco: Jossey-Bass.

Schein, E.H. (1996). Culture: The missing concept in organization studies. Administrative Science Quarterly, 41, 229-240.

Scott, D.K. (1997). Managing organizational culture in intercollegiate athletic organizations. Quest, 49, 403-415.

Shilbury, D., \& Moore, K.A. (2006). A study of organizational effectiveness for national Olympic sporting organizations. Nonprofit and Voluntary Sector Quarterly, 35, 5-38.

Skinner, J., Stewart, B., \& Edwards, A. (1999). Amateurism to professionalism: Modeling organizational change in sporting organizations. Sport Management Review, 2, 173-192.

Slack, T., \& Parent, M.M. (2006). Understanding sport organizations (2nd ed.). Champaign, IL: Human Kinetics.

Smith, A.C.T., \& Shilbury, D. (2004). Mapping cultural dimensions in Australian sporting organizations. Sport Management Review, 7, 133-165.

Smith, A.C.T. (2004). Complexity theory and change management in sport organizations. Emergency: Complexity \& Organization, 6, 70-79.

SPSS. (2005). SPSS Base 14.0 User's Guide. Chicago, IL: SPSS Inc.

Usunier, J. (1998). International \& cross cultural management research. Thousand Oaks, CA: Sage.

Wallach, E. (1983). Individuals and organizations: The cultural match. Training and Development Journal, 2, 28-36.

Wallace, M., \& Weese, W.J. (1995). Leadership, organizational culture, and job satisfaction in Canadian YMCA organizations. Journal of Sport Management, 9, 182-193.

Weese, W.J. (1996). Do leadership and organizational culture really matter? Journal of Sport Management, 10, 197-206.

West, J., \& Graham, J.L. (1998). Language's consequences: A test of linguistic-based measures of culture using Hofstede's dimensions. Paper presented at the Annual Meeting of the Academic of Management, San Diego, CA.

Xenikou, A., \& Furnham, A. (1996). A correlational and factor analytic study of four questionnaire measures of organizational culture. Human Relations, 49, 349-371.

Yeung, K.O., Brockbank, J.W., \& Ulrich, D.O. (1991). Organizational culture and human resource practices: an empirical assessment. Research in Organizational Change and Development, 5, 59-82.

Zammuto, R.F., \& Krakower, J.Y. (1991). Quantitative and qualitative studies of organizational culture. Research in Organizational Change and Development, 5, 83-114. 